\title{
The Double Effect of Customer Interaction in Chinese Short Video APP: The Mediating Role of Brand Experience
}

\author{
Sijia $\mathrm{He}$ \\ School of Management, Shanghai University \\ PO box 201822 Cheng Zhong Street, Jia Ding District, Shanghai, China.
}

\begin{abstract}
In the network age, people have changed from passive reception of information to active creation of information carrier. Everyone can express their ideas and opinions to others, and create value through interaction between customers and customers. In this paper, a theoretical value model is constructed: interaction - brand experience brand loyalty. Based on the mobile application software as the research background, the customer data collected are analyzed by structural equation model. The results show that customer interaction has a positive impact on value creation and brand loyalty, and brand experience has a partial mediating effect on customer value creation and brand loyalty. Finally, it is proposed that enterprises can help enterprises improve brand loyalty by strengthening the construction of customer's emotional relationship network, enhancing customer's continuous use feeling, designing and recommending content through customer segmentation, and expanding customer groups.

Keywords: Customer interaction; short video; value creation; brand loyalty; brand experience
\end{abstract}

DOI: $10.7176 / \mathrm{EJBM} / 11-11-11$

Publication date: April $30^{\text {th }} 2019$

\section{Introduction}

With the rapid development of the network era, in order to meet the needs of users, a variety of mobile applications have emerged, in order to attract more customers. In many mobile applications, the number of video users on mobile terminals has been growing steadily. In December 2017, the statistical report on the development of China's Internet showed that the number of video users on mobile phones in China has reached 579 million. Short video App has become a new favorite of mobile applications. In 2017, the short video market reached 5.73 billion. In this prospect, more enterprises turn their attention to the short video industry.

Under the development of information age, customer interaction has aroused widespread concern among scholars. (Fuller, et al., 2008) argues that customer interaction in the virtual brand community can integrate resources and facilitate product innovation with indirect impact on customer satisfaction. However, in the network era, the interaction between customers is particularly prominent. (Zhang Xin, et al., 2014) Interaction theory has been regarded by scholars as an important cornerstone of service marketing and relationship marketing, and plays an important role in building and maintaining customer relationship. (Guan Hua, Xie Lishan, 2017) believes that customer interaction can create double value.

Although scholars generally emphasize the value created by customer interaction in the Internet, there is still a lack of research on the value of a new media like short video APP. And how to rely on customer interaction, so that enterprises and individuals can gain value, and how to help enterprises improve their brand loyalty, the mechanism behind the formation of what is rarely studied. Based on the perspective of customer interaction between mobile network application clients, this paper studies from the perspective of short video App. Through the interaction process between customers, it can promote brand experience and bring value to enterprises, and help enterprises to enhance their brand loyalty. This paper hopes to help enterprises to gain more market in many short video brands and put forward theoretical suggestions. Therefore, this paper will take "Short Video App's Customer Interaction - Brand Experience - Brand Loyalty" as the research model, and strive to enrich the theoretical research of relevant content, to help enterprises provide practical guidance.

\section{Literature Review and Research Model}

\subsection{Definition of Short Video App}

Short Video APP is a new kind of thing produced under the mobile terminal in the Internet era. (Xiong Chengyu, 2010) Put forward that new media is the sum of media which is based on computer information processing technology and Internet to disseminate information, supervise public opinion, provide entertainment and other functions. It also has the new features of interaction, instantaneity, extension and integration. (Antony, Mayfield, 2008) summarizes social media as interactive, connected and community-based.

Therefore, this paper argues that based on the definition of social media and new media, short video is an application software with two media characteristics, based on UGC (user generated content). Combined with the literature, we find that the characteristics of new media, (Hu Yong, 2012) interaction is a core of new media. (Kuang Wenbo, 2012) "New Media" is precisely expressed as "Digital Interactive Media". (Kim and Ko, 2012) Social media is defined as a variety of online software, media and platforms for interaction and sharing from the 
perspective of user usage purposes. So this paper will study short video based on interaction theory

\subsection{Customer interaction}

With the advent of service-oriented logic and value creation since the beginning of the 21 st century, customer interaction theory has been considered as one of the important topics in service experience research, including customer-employee interaction (Harris and Ezeh, 2008) and customer-to-customer interaction (Yoo et al., 2012). (Florenthal and Shoham, 2010) Regarding interaction as the degree of individual response to specific information providers, there are four ways of interaction: interpersonal interaction, customer-information interaction, customer-media interaction and customer-product interaction.

As short video App is more reflected in the context of interaction with UGC as the main content, this paper will focus on the interaction between customers. (Heeter, 1989) Interactive behavior on the Internet includes six aspects: the complexity of choice, the effort invested, the response of the media, the ability of regulators, the difficulty of adding customers, and interpersonal communication. (Brodie, 2011) Interaction is considered as a specific process between consumers in the virtual brand community, brand and user. Customer interaction is a dynamic process in which customers can obtain emotional, cognitive and behavioral self-satisfaction. This paper argues that the interaction between Short Video App customers lies more in the interaction of video content, whether the video content can be clearly accepted and conveyed to others, and the emotional interaction with other users who create video content. This article will focus on the value of short video App customers' interaction characteristics for the brand. And the mechanism of realizing these values, focusing on the impact of customer interaction on customer value creation and brand loyalty, and the intermediary role of brand experience in this process, the conceptual model is shown in Figure 1.

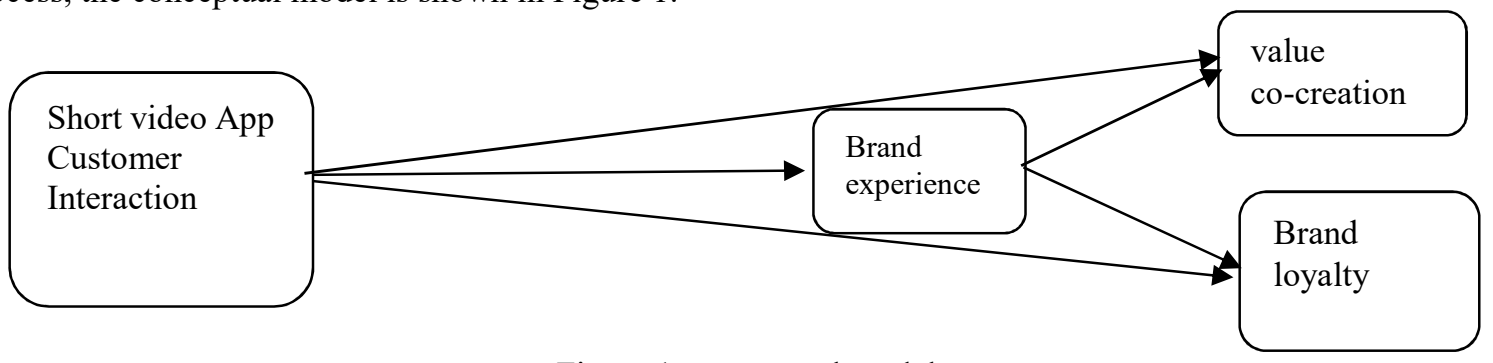

2.2.1 Customer interaction and brand loyalty

Figure 1 .conceptual model

Roger (2004) proposed that the concept of online brand loyalty is to introduce the traditional concept of brand loyalty into online consumer behavior. Bowden (2009) demonstrates that customer interaction can bring brand loyalty and consumer loyalty is the core element of brand equity. Chang (2011) Cultivating brand loyalty is an important goal of building brand communities in e-commerce websites, and interaction in virtual communities is one of the means to achieve it. Niu Zhenbang (2015) pointed out that in order to let customers in the "face" interaction, the "point" interaction and the "intersection" of the interaction of corporate brand has a consistent good impression.

In conclusion, it can be considered that the good interaction between customers in the network era can enhance brand loyalty for enterprises. Therefore, the hypothesis is put forward:

$H_{1}$ : customer interaction has a positive effect on brand loyalty.

2.2.2 Customer interaction and brand experience

Argues that brand experience is the experience of sensory, emotional, thinking, action, and relationship of consumers caused by the components of brand design, packaging and publicity. In the process of using mobile software, we can judge whether to use the brand continuously by the design, content and feeling of the software in the process of using (Brakus, et al., 2009).

verify that the interaction between social media and brand experience is positively related (Su Qisheng, 2015).

Through the understanding of the brand experience, we can know that in the process of customer interaction, we need to use the brand platform to communicate, so the quality of the brand platform to the customer's perceptual experience will have an impact on customer interaction, so we can infer the hypothesis:

$\mathrm{H}_{2}$ : short video App interaction between customers has a positive correlation with brand experience.

2.2.3 Customer interaction and customer value creation

In practice, there exist various pricing schemes in service systems. Per-use pricing is very common in hair salons, cinemas and gas station. In contrast, a health club and a park may sell subscriptions that allow customers to visit without an additional fee (Cachon and Feldman, 2011).

Customer interaction is also a typical form of value creation, which can make customers get better service experience in the service process, and affect their satisfaction and loyalty to the enterprise. Therefore, it is the key to break the boundaries of the domain and the division of the interactive objects produced by the value creation, 
and to explore the interactive behavior of the customer as the core value co-creator. Short video APP highlights the value brought by the original content created by the customer. Therefore, enterprises should actively obtain the opportunity to participate in the process of customer value creation, and become Value co creator (Heinonen, 2010).

Thus, the customer has become the core subject of interaction in the process of value creation, so this paper can make assumptions:

$H_{3}$ : short video app interaction between customers has a positive impact on customer value creation.

2.2.4 Customer co creation value and brand loyalty

Customer value co-creation research is more reflected in consumer and brand communities, with customer content creation as the core, and sharing and displaying with other users, reflecting the uniqueness and value of content. (Pongsakornrungsilp and Schoeder, 2011) believe that the brand community is an important platform for value creation among customers, and customers play the role of both value providers and beneficiaries. Customer-tobusiness interaction is an important way to create value together, and it can bring better experience to customers through sincere and trusted multi-link interaction (Prahalad and Ramaswamy, 2004; Lanier and Hampton, 2008). Value co-creation can make customers get better service experience in the process of service, and affect their satisfaction and loyalty to the enterprise. So this article can assume that:

$\mathrm{H}_{4}$ : customer value co creation has a positive effect on brand loyalty.

2.2.5 The mediating role of brand experience

In the process of interaction between customers and customers, customers will unconsciously experience the related effects brought by brands, and the performance of this effect can reflect the value created by customers in the process of interaction. (Prahalad and Pamaswamy, 2004) In the virtual community brand, customers can interact with the enterprise to create value, and can share with other customers through the experience of value creation. (Brakus, et al. 2009) argue that brand experience is the inherent and behavioral response of customers to direct or indirect contact with the corporate brand, and that the generation process of brand experience is also the response process of customers to the interactive stimulus of a particular brand, so hypotheses can be made:

$\mathrm{H}_{5}$ : brand experience intermediary short video app customer interaction on customer value co creation.

On the other hand, customer interaction can better enable customers to have a general judgment on whether to continue using the brand after experiencing the brand. (Sumino, 2004) demonstrates the impact of brand experience on consumer brand loyalty from the emotional dimension of brand experience.(Pullman, 2004) found that service experience is directly related to brand loyalty of consumers. Domestic scholars (Dong Dahai, 2008) point out that website browsing experience has a positive impact on consumer brand loyalty on the basis of the Internet.Therefore, the hypothesis can be put forward:

$H_{6}$ : brand experience mediator short video app customer interaction on brand loyalty.

\section{Research and design}

This paper designs four variables: customer interaction, brand experience, customer value creation and brand loyalty. Variables were measured by Likert scale.

Customer Interaction: From the point of view of interpersonal communication, interpersonal interaction is often accompanied by information sharing, transmission and emotional communication. Such communication allows people to selectively judge whether to choose to adopt or accept such information and emotions. This paper refers to Nambisan \& Baron's research on measurement information interaction and YOO's research on interpersonal interaction. Questionnaire items such as "I will comment on the video content of interest".

Brand Experience: This is a subjective feeling intention of a person, which is measured by his own judgement of his feelings. The scale was based on Brakus (2009) and the uniqueness of short video app was measured. Customer Value Co-creation: Because customer participation in value co-creation is a measure of customer participation in product innovation. Questionnaire items such as "This short video brand makes me feel selffulfilling".

Customer Participation Value Co-creation refers to the scale of value co-creation developed by ZWASS and Li Chaohui. Questionnaire items such as "I will provide personal creative video for short video App".

Brand loyalty: Measured with a scale from Morgan Hunt (1994). Questionnaire items such as "I will actively recommend the use of this short video brand to my friends around me".

\subsection{Data collection}

The main source of questionnaire collection in this paper is from the Internet. Short video APP is an application software based on mobile client, so this paper can collect questionnaire more effectively through mobile client. A total of 245 valid questionnaires were collected, 66 for males and 179 for females. There is a big difference between men and women. Most of the users who use short video APP are women. The proportion of samples aged 21-30 years accounted for $64.49 \%$. The users of surface short video APP were still the main force of the younger 
generation. The proportion of samples under 20 years old accounted for $25.71 \%$, while the proportion of samples over 31 years old accounted for only $9.8 \%$. This shows that the new generation of young people are more likely to accept new . The education level basically concentrates between undergraduate and master's degree.

\subsection{Customer interaction}

This paper uses SPSS and AMOS to analyze the reliability and validity of the data. The fitting index $X^{\wedge} 2=434.448$, $\mathrm{DF}=230, \mathrm{x}^{\wedge} 2 \mathrm{df}=1.889<3, \mathrm{CFI}=0.961, \mathrm{TLI}=0.954, \mathrm{NFI}=0.922$ are all greater than $0.9 . \mathrm{RMSEA}=0.060$ is greater than 0.05 , but when it is less than 0.08 , the model fits well. Cronbach's alpha $=0.962>0.8$ was obtained by reliability statistical analysis. As shown in Table 1, the combination reliability $(\mathrm{CR})$ of customer interaction, brand experience, customer value co-creation and brand loyalty is greater than 0.7 , which indicates that each measurement scale has a high reliability. The standardized load factor of each item is greater than 0.55 and significant at the level of $\mathrm{a}=0.95$. The variance extraction values (AVE) of all variables were greater than 0.50 , which indicated that they had better aggregation validity. Therefore, according to the data, we can conclude that the reliability and validity of the model have been verified.

Table 1 Confirmative factor analysis and reliability test

\begin{tabular}{|c|c|c|c|c|c|c|}
\hline Construct & Item & $\begin{array}{l}\text { Standardization factor } \\
\text { load }\end{array}$ & $\mathbf{T}$ & $C R$ & $A V E$ & $\begin{array}{l}\text { Cronbach' }^{\prime} \text { s } \\
\alpha\end{array}$ \\
\hline \multirow{4}{*}{ Customer Interaction } & CI1 & 0.673 & - & \multirow{4}{*}{0.821} & \multirow{4}{*}{0.535} & \multirow{4}{*}{0.720} \\
\hline & $\mathrm{CI} 2$ & 0.771 & 9.544 & & & \\
\hline & $\mathrm{CI} 3$ & 0.753 & 8.059 & & & \\
\hline & CI4 & 0.725 & 8.140 & & & \\
\hline \multirow{12}{*}{ Brand Experience } & BE5 & 0.759 & - & \multirow{12}{*}{0.950} & \multirow{12}{*}{0.613} & \multirow{12}{*}{0.952} \\
\hline & BE6 & 0.68 & 12.160 & & & \\
\hline & BE7 & 0.814 & 13.523 & & & \\
\hline & BE8 & 0.848 & 14.178 & & & \\
\hline & BE9 & 0.878 & 14.811 & & & \\
\hline & BE10 & 0.846 & 14.190 & & & \\
\hline & BE11 & 0.756 & 12.406 & & & \\
\hline & BE12 & 0.764 & 12.555 & & & \\
\hline & BE13 & 0.813 & 13.509 & & & \\
\hline & BE14 & 0.788 & 13.009 & & & \\
\hline & BE15 & 0.73 & 11.915 & & & \\
\hline & BE16 & 0.695 & 11.266 & & & \\
\hline \multirow{4}{*}{$\begin{array}{l}\text { Customer } \\
\text { Creation }\end{array}$} & VC17 & 0.915 & - & \multirow{4}{*}{0.918} & \multirow{4}{*}{0.738} & \multirow{4}{*}{0.917} \\
\hline & VC18 & 0.937 & 23.395 & & & \\
\hline & VC19 & 0.811 & 17.477 & & & \\
\hline & VC20 & 0.762 & 14.008 & & & \\
\hline \multirow{4}{*}{ Brand Loyalty } & BL21 & 0.918 & - & \multirow{4}{*}{0.936} & \multirow{4}{*}{0.784} & \multirow{4}{*}{0.942} \\
\hline & BL22 & 0.916 & 23.497 & & & \\
\hline & BL23 & 0.882 & 21.378 & & & \\
\hline & BL24 & 0.823 & 18.159 & & & \\
\hline
\end{tabular}

Table 2 Standard deviations and correlation coefficients of mean values of variables

\begin{tabular}{|c|c|c|c|c|c|c|}
\hline Variable & $\begin{array}{l}\text { average } \\
\text { value }\end{array}$ & $\begin{array}{l}\text { standard } \\
\text { deviation }\end{array}$ & $\begin{array}{l}\text { Customer } \\
\text { interaction }\end{array}$ & $\begin{array}{l}\text { Brand } \\
\text { experience }\end{array}$ & $\begin{array}{l}\text { Customer } \\
\text { value } \\
\text { creation }\end{array}$ & $\begin{array}{l}\text { Brand } \\
\text { loyalty }\end{array}$ \\
\hline $\begin{array}{l}\text { Customer } \\
\text { Interaction }\end{array}$ & 3.398 & 1.107 & & & & \\
\hline $\begin{array}{l}\text { Brand } \\
\text { Experience }\end{array}$ & 3.488 & 1.057 & $0.815 * *$ & & & \\
\hline $\begin{array}{l}\text { Customer } \\
\text { value } \\
\text { Co-Creation }\end{array}$ & 2.948 & 1.209 & $0.461 * *$ & $0.625 * *$ & & \\
\hline Brand Loyalty & 3.653 & 1.145 & $0.186^{*}$ & $0.823 * *$ & $0.185 * *$ & \\
\hline
\end{tabular}

Note: The correlation coefficient between variables is below the diagonal line, $* * \mathrm{P}<0.01, * \mathrm{P}<0.05$. 


\subsection{Customer interaction}

The structural model constructed in this study is used to test the hypothesis. The fitting index of the model is $\mathrm{X}^{\wedge}$ $2=434.448, \mathrm{DF}=230, \mathrm{x}^{\wedge} 2 \mathrm{DF}=1.889<3, \mathrm{CFI}=0.961, \mathrm{TLI}=0.954, \mathrm{NFI}=0.922$ are greater than $0.9, \mathrm{RMSEA}$ $=0.060$ all meet the target requirements, that is, $x^{\wedge} 2$ DF is less than 3, CFI, TLI, NFI, are greater than 0.9 , and SERMA is less than 0.08 . Customer interaction has a positive impact on brand loyalty. The data show that the non-standardized path coefficient is $0.823(\mathrm{t}=8.452, \mathrm{P}<0.01)$, which proves that the friendly interaction between customers and customers in the use process can increase customer loyalty to the brand, assuming $H_{1}$ is verified. In addition, customer interaction has a positive impact on brand experience, and its non-standardized path coefficient is $0.815(\mathrm{t}=8.468, \mathrm{P}<0.01)$. It shows that customer interaction can help customers perceive higher brand experience in the process of using short video APP, assuming $H_{2}$ is verified. Assuming that $H_{3 \text { customer }}$ interaction has a significant impact on customer value co-creation, the non-standardized path coefficient is 0.461 $(t=3.620, p<0.01)$, which shows that customer interaction can effectively improve the value of co-creation. The impact of customer value co-creation on brand loyalty is weaker than that of other variables. The non-standardized path coefficient is $0.185(\mathrm{t}=3.546, \mathrm{P}=0.037<0.05)$, but it can still show that customers can help to rely on the brand when they create value together and thus improve the impact on brand loyalty. It is assumed that $H_{4}$ is validated.

In order to verify the intermediary effect of brand experience, this paper studies the use of Bootstrap function in Amos. The analysis results show that, compared with their total effect, direct effect and indirect effect, we can get that the indirect effect of customer interaction on customer value creation is 0.509 and significant through brand experience. The effect is 0.970 , assuming that $H_{5}$ is verified. The direct impact of customer interaction on brand loyalty is 0.186 , but not significant ( $95 \%$ confidence interval contains 0$)$. The total indirect impact of cocreation through brand experience and customer value is 0.850 and significant, and the total effect is 1.036 .

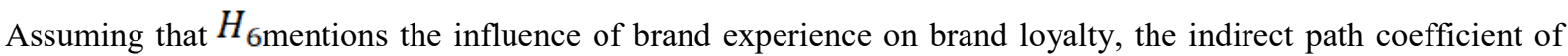
customer interaction to brand loyalty is 0.671 only through the influence of brand experience, so the hypothesis is verified, and all the above hypotheses are verified.

Table 3 Analysis of direct, indirect and total effects of non-standardization

\begin{tabular}{|c|c|c|c|c|c|c|c|c|}
\hline \multirow[t]{3}{*}{ Effect } & \multirow{3}{*}{$\begin{array}{l}\text { Variable } \\
\text { relationship }\end{array}$} & \multirow{3}{*}{$\begin{array}{l}\text { Point } \\
\text { estimation } \\
\text { Count } \\
\text { value }\end{array}$} & \multirow{3}{*}{$\begin{array}{l}\text { Standard } \\
\text { error }\end{array}$} & \multicolumn{4}{|c|}{ Bootstrapping } & \multirow{3}{*}{$\begin{array}{l}\text { Two- } \\
\text { tailed test }\end{array}$} \\
\hline & & & & \multicolumn{2}{|c|}{ Bias-corrected $95 \% \mathrm{CI}$} & \multicolumn{2}{|c|}{ Percenttile95\%CI } & \\
\hline & & & & Lower & Upper & Lower & Upper & \\
\hline \multirow{3}{*}{$\begin{array}{l}\text { CI-CV } \\
\text { CI-VC }\end{array}$} & Total effect & 0.970 & 0.124 & 0.750 & 1.247 & 0.745 & 1.236 & $\begin{array}{l}0.0 \\
(* *)\end{array}$ \\
\hline & $\begin{array}{l}\text { Direct } \\
\text { Effect }\end{array}$ & 0.461 & 0.150 & 0.214 & 0.798 & 0.215 & 0.799 & $\begin{array}{l}0.0 \\
(* *)\end{array}$ \\
\hline & $\begin{array}{l}\text { Indirect } \\
\text { Effect }\end{array}$ & 0.509 & 0.106 & 0.319 & 0.745 & 0.292 & 0.716 & $\begin{array}{l}0.0 \\
(* *)\end{array}$ \\
\hline
\end{tabular}

\begin{tabular}{|c|c|c|c|c|c|c|c|c|}
\hline \multirow[t]{3}{*}{ Effect } & \multirow{3}{*}{$\begin{array}{l}\text { Variable } \\
\text { relationship }\end{array}$} & \multirow{3}{*}{$\begin{array}{l}\text { Point } \\
\text { estimation } \\
\text { Count value }\end{array}$} & \multirow{3}{*}{$\begin{array}{l}\text { Standard } \\
\text { error }\end{array}$} & \multicolumn{4}{|c|}{ Bootstrapping } & \multirow{3}{*}{$\begin{array}{l}\text { Two- } \\
\text { tailed } \\
\text { test }\end{array}$} \\
\hline & & & & \multicolumn{2}{|c|}{$\begin{array}{l}\text { Bias- } \\
\text { corrected } 95 \% \mathrm{CI}\end{array}$} & \multicolumn{2}{|c|}{ Percenttile95\%CI } & \\
\hline & & & & Lower & Upper & Lower & Upper & \\
\hline \multirow{3}{*}{ CI-BL } & 总效果 & 1.036 & 0.127 & 0.809 & 1.304 & 0.815 & 1.317 & $\begin{array}{l}0.00 \\
(* *)\end{array}$ \\
\hline & 直接效果 & 0.186 & 0.115 & -0.031 & 0.423 & -0.023 & 0.431 & $\mathrm{P}>0.05$ \\
\hline & 总间接效果 & 0.850 & 0.105 & 0.674 & 1.088 & 0.664 & 1.071 & $\begin{array}{l}0.00 \\
(* *)\end{array}$ \\
\hline
\end{tabular}

Note: CI - customer interaction, VC - customer value creation, BL - brand loyalty, BE - brand experience. Nonstandardized estimates of 5000 Bootstrap samples.

\section{Research conclusions and discussions}

4.1 Research conclusions

This paper studies the application of new media such as short video APP, and explores its intrinsic mechanism by studying the interactive influence mechanism of its characteristics on brand loyalty. The highly interactive mode of application software on the Internet has a prominent impact on helping brand value creation and improving customer loyalty. Therefore, through combing the previous literature, this paper puts forward the model of 
customer interaction - brand loyalty for research and investigation. It also finds that customer interaction has a positive impact on value creation, and can help enterprises enhance their brand loyalty. In the above model, brand experience is used as a mediating role, that is, customer interaction can help enterprises improve brand loyalty through brand experience intermediary. This study contributes to the following two aspects.

(1) The value of interaction between customers in mobile applications. In the past, the research interaction mostly lies in experiencing the interaction between customers and enterprises. However, on the basis of the Internet, customer groups prefer to show themselves to other users. From this study, we can see that customer-customer sharing, communication and communication can further expand the research on the impact of customer value creation and corporate loyalty.

(2) The mechanism of customer interaction affecting brand loyalty is discussed. Although it is generally accepted that interaction can bring value to enterprises, there is still a lack of relevant research on how the interaction mechanism works. This study is based on the interaction between customers and customers, using short video APP as the medium, which shows that customers and customers can bring value to enterprises. The experience of customer interaction is a very important emotional compensation, which mediates customer interaction and brand loyalty. Empirical research shows that brand experience in short video APP mediates the influence of customer interaction and customer value creation, and plays a role in customer interaction and brand loyalty. To the role of complete intermediary, we can see that brand loyalty needs to be judged by the perception of the use of its brand in the process of customer interaction, while in the process of customer interaction and customer value creation, the sharing discussion and communication between customers and customers is in the process of value transmission, so this paper. It provides a theoretical basis for the construction of the relationship between customer interaction theory and brand loyalty.

\subsection{Management inspiration}

The conclusion of this paper can be used for reference in how to establish and maintain the brand of highly interactive mobile client application in management practice and improve the value created by customer interaction. Firstly, the application software of mobile client can take measures to effectively promote the interaction between customers and customers, which requires managers to subdivide the customer groups and explore different types of customers to recommend different content modes for different types of customers who want to share and communicate. By strengthening the relationship between customers and other customers in the process of using software, strengthening the emotional relationship network between customers, helping enterprises to better retain customers. Secondly, brand experience completely mediates the interaction between customers and brand loyalty. Enterprises need to increase the experience of customers in the process of using software. Do more testing in the early stage of a software update, integrate customer's word of mouth and response, and continuously improve customer's experience in the use process. Third: Although the customer groups of users using short video APP are concentrated in the younger group under 30 years of age, most of the middle-aged and elderly people have more time for self-determination because of the current aging situation in China. Therefore, it is suggested that enterprises can design the content that the middle-aged and elderly customers like, and targeted. The design is suitable for the interface between the middle-aged and the elderly, reducing the complexity of the software use process can effectively help enterprises improve the experience of the middle-aged and the elderly using software.

\subsection{Deficiencies and Prospects}

Although this paper uses scientific research methods to investigate customer interaction, it still finds that there are limitations and shortcomings in this study. Firstly, the research in this paper is limited to short video APP. Although we think this model is universal for mobile application software, whether its conclusion is applicable to other types of mobile application software needs further research to verify. Secondly, the limitation of this research is that the cross-sectional data are used in the survey, which can only explain the correlation between variables and variables, but can not explain the causality well. But the interaction between customers is a dynamic process, and the interaction between people is a complex process, which is repeated many times, when needed. Accumulation between them requires data collection from different time points to make the conclusions more reliable and accurate. Thirdly, this paper only investigates and studies the interaction between customers, without considering the other value or negative impact of the promotion factors of customer interaction. How to help enterprises make long-term and better connection between customers and customers is still lacking. Fourthly, the interaction of information between customers and customers, how to avoid the negative impact of some unhealthy information transmission need to be further discussed, and how to control and deal with the negative impact between customers and customers is also a challenge. At the same time, whether the quality of interactive content brought by customers has an impact on the development of customer interaction needs further discussion. Future research can be carried out to discuss the value of interactive content. In addition, the interaction between customers is more prominent and the relationship between people, so the process of emotional and psychological activities is discussed. Although this kind of software highlights the interaction between customers and customers, there are 
still different interactive themes brought about by customers and enterprises, customers and employees, customers and the environment. Value, this is also the follow-up can be worth exploring and studying.

\section{References}

Antony Mayfield.( 2008). What is Social Media. (8):6-8.

Bela Florenthal, \& Aviv Shoham. (2010) Four-mode channel interactivity concept and channel preferences. Journal of Services Marketing, 24(1).

Bemers-Lee T.HaLL W.HendlerJ, O’Hara K, \&Shadbolt N .Weitzner D. (2006). A framework for Web science. Foundations and Trends in Web Science, 1(1)1:1-30.

Brakus,J. J,Schmitt, B.H, Zarantonello, L. (2009). Brand experience: What is it? How is it measured? Does it affect loyalty?. Journal of Marketing,73(5):52-68.

Chang, Y. P,Zhu, D. H,Wang, S. H. (2011). The influence of online game service quality on loyalty:An empirical study of MMORPGs. Social Behavior and Personality,39(10):1297-1302.

C.K. Prahalad,Venkat Ramaswamy. (2004). Co-creation experiences: The next practice in value creation. Journal of Interactive Marketing,18(3).

C.K. Prahalad, Venkat Ramaswamy. (2004). Co-creating unique value with customers. Strategy \& Leadership, 32 (3): 4-9.

Dong Dahai, Yang Yi. (2008). Theoretical Analysis of Consumer Perceived Value in Internet Environment. Journal of Management, (06): 856-861

Fuller J. Matzler K. Hoppe M. (2008). Brand community members as a source of innovation. Journal Of Product Innovation Management, 25(6):608-619.

Guan Xinhua, Xie Lishan. (2017). Dual Value of Customer Interaction: Intermediate Role of Knowledge Exchange Quality. Journal of Marketing Science, 13 (01): 55-66.

Heinonen K, Strandvik T, Mickelsson K J. (2010). A Customer-domi-nant Logic of Service. Journal of Service Management,21(4):531-548.

Jaewon (Jay) Yoo, Todd J. Arnold, Gary L. Frankwick. Effects of positive customer-to-customer service interaction. Journal of Business Research,2012,65(9).

Kim A J. Ko E. Do social media marketing activities enhance customer equity? an empirical study of luxury fashion brand. Journal of Business Research,2012(10):1480-1486.

Loyd C. Harris, Chris Ezeh. Servicescape and loyalty intentions: an empirical investigation. European Journal of Marketing,2008,42(3/4).

Lusch. Toward a conceptual foundation for service science: Contributions from service-dominant logic.IBM Systems Journal, 2008, Vol.47 (1), pp.5-14.

Niu Zhenbang, Bai Changhong, Zhang Hui, Chen Ye. (2015). Shallow interaction can stimulate customer value co-creation willingness-A mixed effect model based on brand experience and value proposition fit. Science and Technology Management,36(11): 112-123.

Pullman M E, Gross M A. (2014). Ability of experience design elements to elicit emotions and loyalty behaviors. Decision Sciences, 35(3): 551-578.

R. J. Brodie, L. D. Hollebeek, B. Juric, A. Ilic Customer Engagement: Conceptual Domain, Fundamental Propositions, and Implications for Research. Journal of Service Research, 2011, Vol.14 (3): 252-271.

Roger Loosley, Stuart Richards, Joanne Gregory. (2004). The effect on brand management when a business migrates onto the internet. Brand Management, (4):267.

Sheth,J. N. 1976.Buyer-Seller Interaction: A Conceptual Framework. Advances in Consumer Research 3(1):382386.

Stephen L. Vargo,Paul P. Maglio,Melissa Archpru Akaka. On value and value co-creation: A service systems and service logic perspective. European Management Journal,2008,26(3).

Sumino M, Harada M. (2004). Affective experience of J. League Fans: the relationship between affective experience, team loyalty and intention to attend. Managing Leisure, 9: 181-192.

Xiong Chengyu, Lu Yuxiang, Zhang Zheng. (2010). New Media and Media Reform in China: 1978-2008. Journal of Tsinghua University (Philosophy and Social Sciences), 25 (01): 127-132.

Yoo J, Amold T J, Frankwick G L. (2012). Effects of positive customer-to-customer service interaction. Journal of Business Research,65:1313-1320.

Zhang Xin, Yang Zhiyong, Wang Yonggui. (2014) Review on the Frontier Research of Customer Interaction: Connotation, Dimension, Measurement and Theory Evolution. Journal of International Business (University of Foreign Economics and Trade), (04): 86-94. 